\title{
EXPLORATORY SPECTRAL ANALYSIS IN THREE-DIMENSIONAL SPATIAL POINT PATTERNS
}

\author{
Edmary Silveira BARRETO ARAÚJO ${ }^{1}$ \\ João Domingos SCALON ${ }^{2}$ \\ Lurimar Smera BATISTA ${ }^{1}$
}

- ABSTRACT: A spatial point pattern is a collection of points irregularly located within a bounded area (2D) or space (3D) that have been generated by some form of stochastic mechanism. Examples of point patterns include locations of trees in a forest, of cases of a disease in a region, or of particles in a microscopic section of a composite material. Spatial Point pattern analysis is used mostly to determine the absence (completely spatial randomness) or presence (regularity and clustering) of spatial dependence structure of the locations. Methods based on the space domain are widely used for this purpose, while methods conducted in the frequency domain (spectral analysis) are still unknown to most researchers. Spectral analysis is a powerful tool to investigate spatial point patterns, since it does not assume any structural characteristics of the data (ex. isotropy), and uses only the autocovariance function, and its Fourier transform. There are some methods based on the spectral frameworks for analyzing 2D spatial point patterns. There is no such methods available for the $3 \mathrm{D}$ situation and, therefore, the aim of this work is to develop new methods based on spectral framework for the analysis of three-dimensional point patterns. The emphasis is on relating periodogram structure to the type of stochastic process which could have generated a 3D observed pattern. The results show that the methods based on spectral analysis developed in this work are able to identify patterns of three typical three-dimensional point processes, and can be used, concurrently, with analyzes in the space domain for a better characterization of spatial point patterns.

- KEYWORDS: Spatial statistics; point processes; frequency domain; Fourier transform; periodogram.

\footnotetext{
${ }^{1}$ Instituto Federal da Bahia - IFBA, Departamento de Matemática, CEP: 40301-015, Salvador, BA, Brasil..E-mail: ebarreto@ifba.edu.br; lurimar@ifba.edu.br

${ }^{2}$ Universidade Federal de Lavras - UFLA, Instituto de Ciências Exatas e Tecnológicas, Departamento de Estatística, CEP: 37200-900, Lavras, MG, Brasil. E-mail: scalon@ufla.br
} 


\section{Introduction}

In the study of spatial point processes, each event can be idealized as a point, and the irregular distribution of the events generated by the point process within a bounded region $(2 \mathrm{D}$ or $3 \mathrm{D})$ is called a spatial point pattern. The primary stochastic component is the spatial location of the event and, thus, the data of interest is the coordinate of each of these events in the study region (BADDELEY et al., 2015; DIGGLE, 2003).

The analysis of point patterns is of interest in many different areas of research such as ecology, epidemiology, and composite materials to name but a few. In epidemiology, for example, a common problem is to determine whether the cases of a certain disease are clustered.

The main aim of the spatial point pattern analysis is to characterize how individuals are located with respect to each other over the space. The analysis is conducted to characterize the three fundamental spatial point patterns: complete spatial randomness (CSR), regularity and clustering (DIGGLE, 2003).

Statistical methods for spatial point pattern analysis have been base on "space-domain" techniques that involve the examination of inter-point distances within a bounded essentially planar region (BADDELEY et al., 2015; DIGGLE, 2003). Lately, we have observed the increased ability to capture data through three-dimensional materials, and thus it has been made it possible to extend those $2 \mathrm{D}$ space-domain methods to the 3D point patterns analysis (BRAENDGAAR and GANDERSEN, 1986; BADDELEY et al., 1993, 2015).

Although, the ideas of spectral analysis are widespread and applied in several areas of knowledge (e.g. signal processing, time series), their potential for analyzing spatial point patterns is still unexplored (MUGGLESTONE and RENSHAW, 1996). Bartlett (1964) was the pioneer in suggesting the use of spectral analysis in point processes, while Renshaw and Ford (1984) and Mugglestone and Renshaw (1996, 2001) have shown how the spectral framework can be an important tool for exploratory analysis of $2 \mathrm{D}$ spatial point patterns. These two-dimensional spectral methods was applied with success by Araújo et al. (2014) in order to investigate the the spatial patterns of silicon carbide particles located in an aluminum alloy matrix $(\mathrm{Al} / \mathrm{SiC})$.

Although, spectral framework has shown to be a powerful tool for the investigation of $2 \mathrm{D}$ spatial point patterns, since it does not assume any structural characteristics of the stochastic point process (e.g. isotropy), and it is based on the autocovariance function, and its Fourier transform, there is no developed theory based on the "frequency domain" for the 3D spatial point pattern analysis.

The aim of this work is to develop new methods based on the spectral framework that can be used as a tool for the exploratory analysis of threedimensional spatial point patterns. The emphasis will be on relating periodogram structure to the type of typical simulated point patterns. 


\section{Three-dimensional spectral function}

The methodology for point patterns in volume has not yet been fully explored, being slightly addressed by Baddeley et al. (1993). The methodology can be developed as an extension of the theory in two-dimensional point processes.

As in the plane, different spatial point processes can be distinguished by comparing their first and second order properties.

The first-order three-dimensional intensity function, expanding the twodimensional case, is defined as:

$$
\lambda(s)=\lim _{\operatorname{vol}(B) \rightarrow 0}\left[\frac{E[N(B)]}{\operatorname{vol}(B)}\right],
$$

where $E[\quad]$ denotes the expected value, $B \subset R^{3}$ is an infinitesimal region around the point $s=\left(s_{i}, s_{j}, s_{k}\right)$, and $\operatorname{vol}(B)$ is the volume of this space.

The three-dimensional second-order intensity function, for $s \neq r$, is defined as:

$$
\lambda(s, r)=\lim _{\operatorname{vol}(B) \rightarrow 0 \operatorname{vol}(C) \rightarrow 0}\left[\frac{E[N(B) N(C)]}{\operatorname{vol}(B) \operatorname{vol}(C)}\right] .
$$

where $B, C \subset R^{3}, B$ is an infinitesimal region around the point $s=\left(s_{i}, s_{j}, s_{k}\right)$ with $\operatorname{vol}(B)$ being the volume of this space. $C$ is an infinitesimal region around the point $r=\left(r_{i}, r_{j}, r_{k}\right)$ where $\operatorname{vol}(C)$ is the volume of this space.

The covariance density function for the three-dimensional case is defined in equation (3). Also, expanding the two-dimensional case, we have

$$
\gamma(s, r)=\lim _{\operatorname{vol}(B) \rightarrow 0 \operatorname{vol}(C) \rightarrow 0}\left[\frac{E[\{N(B)-\lambda(B)\}\{N(C)-\lambda(C)\}]}{\operatorname{vol}(B) \operatorname{vol}(C)}\right],
$$

where $s \in B \subset R^{3}$, and $r \in C \subset R^{3}$.

Developing the equation (3) we have

$\gamma(s, r)=\lim _{\operatorname{vol}(B) \rightarrow 0 \operatorname{vol}(C) \rightarrow 0}\left[\frac{E[N(B) N(C)-N(B) \lambda(C)-\lambda(B) N(C)+\lambda(B) \lambda(C)]}{\operatorname{vol}(B) \operatorname{vol}(C)}\right]$.

Using the property of the sum limit and the property of the mathematical expectation of the sum of two random variables, that is, $E[X+Y]=E[X]+E[Y]$ in the equation (4), we have

$$
\begin{aligned}
\gamma(s, r) & = \\
& =\lim _{\operatorname{vol}(B) \rightarrow 0 \operatorname{vol}(C) \rightarrow 0}\left[\frac{E[N(B) N(C)]}{\operatorname{vol}(B) \operatorname{vol}(C)}\right]-\lim _{\operatorname{vol}(B) \rightarrow 0 \operatorname{vol}(C) \rightarrow 0}\left[\frac{E[N(B) \lambda(C)]}{\operatorname{vol}(B) \operatorname{vol}(C)}\right] \\
& -\quad \lim _{\operatorname{vol}(B) \rightarrow 0 \operatorname{vol}(C) \rightarrow 0}\left[\frac{E[\lambda(B) N(C)]}{\operatorname{vol}(B) \operatorname{vol}(C)}\right]+\lim _{\operatorname{vol}(B) \rightarrow 0 \operatorname{vol}(C) \rightarrow 0}\left[\frac{E[\lambda(B) \lambda(C)]}{\operatorname{vol}(B) \operatorname{vol}(C)}\right]
\end{aligned}
$$


We observe that in equation (5), the first limit corresponds to the equation (2), whereas the regions are disjoint.

Thus, we have

$$
\begin{gathered}
E[N(B) \lambda(C)]=E[N(B)] E[\lambda(C)], \\
E[\lambda(B) N(C)]=E[\lambda(B)] E[N(C)] \quad \text { and } E[\lambda(B) \lambda(C)]=E[\lambda(B)] E[\lambda(C)],
\end{gathered}
$$

because the spaces are independents.

When the volume of $B(\operatorname{vol}(B))$ and the volume of $C(\operatorname{vol}(C))$ approach to zero, $\lambda(B)$ tends to $\lambda(s)$ e $\lambda(C)$ tends to $\lambda(r)$, respectively.

Considering the fact that

$$
\lambda(s)=\lim _{\operatorname{vol}(B) \rightarrow 0}\left[\frac{E[N(B)]}{\operatorname{vol}(B)}\right],
$$

and

$$
\lambda(r)=\lim _{\operatorname{vol}(C) \rightarrow 0}\left[\frac{E[N(C)]}{\operatorname{vol}(C)}\right],
$$

then, the equation (5) is:

$$
\gamma(s, r)=\lambda(s, r)-\lambda(s) \lambda(r)-\lambda(s) \lambda(r)+\lambda(s) \lambda(r) .
$$

or yet,

$$
\gamma(s, r)=\lambda(s, r)-\lambda(s) \lambda(r) .
$$

The equation (3) is related to equation (1) and equation (2) by equation (6).

The definition of covariance density function in the equation (3) for $s \neq r$. This can be extended to include the case $s=r$, assuming that the process is ordered, that is, $P[N(B)>1]=0$, and, therefore,

$$
E\left[N(B)^{2}\right]=E[N(B)]=\lambda(s) \operatorname{vol}(B)
$$

Thus, the complete covariance density function is given by

$$
k(s, r)=\lambda(s) \delta\left(s_{i}-r_{i}\right) \delta\left(s_{j}-r_{j}\right) \delta\left(s_{k}-r_{k}\right)+\gamma(s, r),
$$

where $\delta$ is the Dirac delta.

The three-dimensional spectral density function is defined as the Fourier transform of the complete covariance function, and may be obtained from the expansion of the theory presented in Bartlett (1964).

Let $f: R^{3} \rightarrow C$ be an integrable function, then a three-dimensional Fourier transform $\Im\{f(p, q, t)\}=F\left(w_{p}, w_{q}, w_{t}\right)$ is defined by

$$
F\left(w_{p}, w_{q}, w_{t}\right)=\int_{R^{3}} f(p, q, t) e^{-i\left(w_{p} p+w_{q} q+w_{t} t\right)} d p d q d t
$$

where $w_{p}, w_{q}$ e $w_{t}$ are frequencies and $C$ is a set of complex numbers.

The power spectrum of the three-dimensional Fourier transform is defined by 


$$
P=\left\{\Re\left\{F\left(w_{p}, w_{q}, w_{t}\right)\right\}\right\}^{2}+\left\{\operatorname{Im}\left\{F\left(w_{p}, w_{q}, w_{t}\right)\right\}\right\}^{2}=\left|F\left(w_{p}, w_{q}, w_{t}\right)\right|^{2},
$$

with phase angle

$$
\phi=\arctan \left\{\frac{\operatorname{Im}\left\{F\left(w_{p}, w_{q}, w_{t}\right)\right\}}{\Re\left\{F\left(w_{p}, w_{q}, w_{t}\right)\right\}}\right\} .
$$

Bartlett(1964) advocates to use the density function of the complete covariance as an alternative to describe a spatial point process in order to perform the spectral analysis. The spectral density function of a point process (or spectrum point) is defined as the Fourier transform of the density function of the complete covariance. It can be formally defined in a three-dimensional space as

$$
f\left(w_{p}, w_{q}\right)=\int_{R^{3}} \int_{R^{3}} k(s, r) e^{-i\left(w_{p}^{\top} s+w_{q}^{\top} r\right)} d s d r
$$

$s \in R^{3}, r \in R^{3}$, with inverse given by

$$
k(s, r)=\int_{R^{3}} \int_{R^{3}} f\left(w_{p}, w_{q}\right) e^{i\left(w_{p}^{\top} s+w_{q}^{\top} r\right)} d w_{p} d w_{q},
$$

where $w_{p} \in P \subset R^{3}$ and $w_{q} \in Q \subset R^{3}$ and $T$ denotes transpose.

Substituting equation (8) in the equation (12), we get a more general spectral density function as follows:

$$
\begin{aligned}
f\left(w_{p}, w_{q}\right) & =\int_{R^{3}} \int_{R^{3}} \lambda(s) \delta\left(s_{i}-r_{i}\right) \delta\left(s_{j}-r_{j}\right) \delta\left(s_{k}-r_{k}\right) e^{-i\left(w_{p}^{\top} s+w_{q}^{\top} r\right)} d s d r \\
& +\int_{R^{3}} \int_{R^{3}} \gamma(s, r) e^{-i\left(w_{p}^{\top} s+w_{q}^{\top} r\right)} d s d r
\end{aligned}
$$

In the case of a three-dimensional isotropic point process where $c=\left(c_{i}, c_{j}, c_{k}\right)$, we get the equation (14) in the following form

$$
f\left(w_{p}, w_{q}, w_{t}\right)=\lambda+\int_{-\infty}^{\infty} \int_{-\infty}^{\infty} \int_{-\infty}^{\infty} \gamma\left(c_{i}, c_{j}, c_{k}\right) e^{\left\{-i\left(w_{p} c_{i}+w_{q} c_{j}+w_{t} c_{k}\right)\right\}} d c_{i} d c_{j} d c_{k}
$$

where $\left(w_{p}, w_{q}, w_{t}\right) \in R^{3}$.

Proof:

An isotropic point process has constant first order intensity $\lambda(s)=\lambda$. In this case, the covariance function depends only on the distance and not on the direction, that is, $\gamma(s, r)=\gamma(c)$, where $c=s-r$, for $s=\left(s_{i}, s_{j}, s_{k}\right)$ and $r=\left(r_{i}, r_{j}, r_{k}\right)$. Therefore, the equation (14) is given by

$$
\begin{aligned}
f\left(w_{p}, w_{q}, w_{t}\right) & =\int_{-\infty}^{\infty} \int_{-\infty}^{\infty} \int_{-\infty}^{\infty} \lambda \delta\left(s_{i}-r_{i}\right) \delta\left(s_{j}-r_{j}\right) \delta\left(s_{k}-r_{k}\right) \\
& \cdot e^{\left\{-i\left(w_{p} c_{i}+w_{q} c_{j}+w_{t} c_{k}\right)\right\}} d c_{i} d c_{j} d c_{k} \\
& +\int_{-\infty}^{\infty} \int_{-\infty}^{\infty} \int_{-\infty}^{\infty} \gamma(c) e^{\left\{-i\left(w_{p} c_{i}+w_{q} c_{j}+w_{t} c_{k}\right)\right\}} d c_{i} d c_{j} d c_{k}
\end{aligned}
$$


where $\left(w_{p}, w_{q}, w_{t}\right) \in R^{3}$.

If the Fourier transform of the Dirac delta function is equal to one, the equation (16) can be written as

$$
f\left(w_{p}, w_{q}, w_{t}\right)=\lambda+\int_{-\infty}^{\infty} \int_{-\infty}^{\infty} \int_{-\infty}^{\infty} \gamma(c) e^{\left\{-i\left(w_{p} c_{i}+w_{q} c_{j}+w_{t} c_{k}\right)\right\}} d c_{i} d c_{j} d c_{k}
$$

where $\left(w_{p}, w_{q}, w_{t}\right) \in R^{3}$.

The three-dimensional discrete Fourier transform of the coordinates is defined as

$$
F(p, q, t)=\sum_{j=1}^{N_{x}} e^{-2 \pi i\left(\frac{p x_{1 j}}{l_{1}}+\frac{q x_{2 j}}{l_{2}}+\frac{q x_{3 j}}{l_{3}}\right)}=A(p, q, t)+i B(p, q, t),
$$

where $N_{x}$ is the number of events within a bounded three-dimensional space of sides $l_{1}, l_{2}$, where $l_{3}$ and $\left(x_{1 j}, x_{2 j}, x_{3 j}\right)$ denotes the location of the events for $j=1, \ldots, N_{x}$.

The periodogram, also known as the sample spectral function, can be calculated as the power spectrum of the discrete Fourier transform of the coordinates as

$$
\hat{f}\left(w_{p}, w_{q}, w_{t}\right)=|F(p, q, t)|^{2}=\{A(p, q, t)\}^{2}+\{B(p, q, t)\}^{2},
$$

where

$$
\left(w_{p}, w_{q}, w_{t}\right)=\left(\frac{2 \pi p}{l_{1}} \frac{2 \pi q}{l_{2}}, \frac{2 \pi t}{l_{3}}\right) .
$$

The coordinate of the periodogram, or the real part of the discrete Fourier transform, has asymptotically Normal distribution $\left(N_{x} \rightarrow \infty\right)$ with mean $(\mu(A))$ equal to zero e variance $(V(A))$ equal to the spectral function divided by two (MUGGLESTONE and RENSHAW, 1996). Thus, for the three-dimensional case, we have

$$
A(p, q, t) \sim N\left(0, \frac{f\left(w_{p}, w_{q}, w_{t}\right)}{2}\right), \quad\left(w_{p}, w_{q}, w_{t}\right) \neq(0,0,0) .
$$

If $\left(w_{p}, w_{q}, w_{t}\right)=(0,0,0)$, thus $A(0,0,0)$ has asymptotically Normal distribution with mean $(\mu(A))=\lambda$, and variance $(V(A))$ equal to the spectral function divided by two in $\left(w_{p}, w_{q}, w_{t}\right)=(0,0,0)$ and, therefore,

$$
A(0,0,0) \sim N\left(\lambda, \frac{f(0,0,0)}{2}\right) .
$$


The imaginary part of the discrete Fourier transform also has an asymptotic Normal distribution with mean $(\mu(B))$ equal to zero and variance $(V(B))$ equal to the spectral function divided by two. Thus, for the three-dimensional case, we have

$$
B(p, q, t) \sim N\left(0, \frac{f\left(w_{p}, w_{q}, w_{t}\right)}{2}\right), \quad\left(w_{p}, w_{q}, w_{t}\right) \neq(0,0,0) .
$$

$B(0,0,0)=0$, where $A(p, q, t)$ and $B(p, q, t)$ are asymptotically independents.

Considering $\left(w_{p}, w_{q}, w_{t}\right) \neq(0,0,0)$, we have

$$
\frac{2 \hat{f}\left(w_{p}, w_{q}, w_{t}\right)}{f\left(w_{p}, w_{q}, w_{t}\right)} \sim \chi_{2}^{2}, \quad\left(w_{p}, w_{q}, w_{t}\right) \neq(0,0,0)
$$

Proof: If $A(p, q, t)$ e $B(p, q, t)$ have distributions (21) and (23), respectively, them

$$
\frac{A(p, q, t)-\mu(A)}{\sqrt{\operatorname{Var}(A)}} \sim N(0,1)
$$

and

$$
\frac{B(p, q, t)-\mu(B)}{\sqrt{\operatorname{Var}(B)}} \sim N(0,1) .
$$

If $Z_{1}, Z_{2}, \ldots, Z_{n}$ are standard normal random variables, thus

$$
\sum_{i=1}^{n} Z_{i}^{2} \sim \chi_{n}^{2}
$$

It can be proved that if two random variables have known and equal momentgenerating functions, then they have the same distribution function (MAGALHÃES, 2006).

Let

$$
U=\sum_{i=1}^{n} Z_{i}^{2}
$$

Then, the moment-generating function of $\mathrm{U}$ is given by

$$
\begin{aligned}
E\left(e^{t} U\right) & =E\left(e^{t} \sum_{i=1}^{n} Z_{i}^{2}\right)=E\left(e^{t} Z_{1}^{2}\right) \ldots E\left(e^{t} Z_{n}^{2}\right) \\
& =\prod_{i=1}^{n} E\left(e^{t Z_{i}^{2}}\right)=\prod_{i=1}^{n}\left(\frac{1}{\sqrt{(1-2 t)}}\right) \\
& =\left(\frac{1}{1-2 t}\right)^{\frac{n}{2}}, t<\frac{1}{2},
\end{aligned}
$$


where $\left(\frac{1}{1-2 t}\right)^{\frac{n}{2}}, t<\frac{1}{2}$ is the moment-generating function of the distribution $\chi_{n}^{2}$. Therefore,

$$
\frac{\hat{f}\left(w_{p}, w_{q}, w_{t}\right)}{\frac{f\left(w_{p}, w_{q}, w_{t}\right)}{2}}=\frac{(A(p, q, t)-0)^{2}}{\frac{f\left(w_{p}, w_{q}, w_{t}\right)}{2}}+\frac{(B(p, q, t))^{2}}{\frac{f\left(w_{p}, w_{q}, w_{t}\right)}{2}}=Z_{1}^{2}+Z_{2}^{2} .
$$

that is,

$$
\frac{2 \hat{f}\left(w_{p}, w_{q}, w_{t}\right)}{f\left(w_{p}, w_{q}, w_{t}\right)} \sim \chi_{2}^{2}, \quad\left(w_{p}, w_{q}, w_{t}\right) \neq(0,0,0) .
$$

In the case of $\left(w_{p}, w_{q}, w_{t}\right)=(0,0,0)$, we have

$$
\frac{2 \hat{f}(0,0,0)-\lambda}{f(0,0,0)} \sim \chi_{1}^{2}
$$

Proof:

Let $\left(w_{p}, w_{q}, w_{t}\right)=(0,0,0)$, thus

$$
\frac{2 \hat{f}\left(w_{p}, w_{q}, w_{t}\right)}{f(0,0,0)}=\frac{\hat{f}(0,0,0)}{\frac{f(0,0,0)}{2}}=\frac{(A(0,0,0)-\lambda)^{2}+(B(0,0,0))^{2}}{\frac{f(0,0,0)}{2}} .
$$

Considering $B(0,0,0)=0$, thus

$$
\frac{\hat{f}(0,0,0)}{\frac{f(0,0,0)}{2}}=\frac{(A(0,0,0)-\lambda)^{2}}{\frac{f(0,0,0)}{2}} .
$$

and, therefore,

$$
\frac{(A(0,0,0)-\lambda)^{2}}{\frac{f(0,0,0)}{2}}=Z_{1}^{2}
$$

that is,

$$
\frac{2 \hat{f}(0,0,0)-\lambda}{f(0,0,0)} \sim \chi_{1}^{2}
$$

An advantage of the spectral analysis in relation to the analysis in the space domain is the possibility to evaluate the point pattern considering both the scale and the direction. In the three-dimensional case, each $\hat{f}\left(w_{p}, w_{q}, w_{t}\right)$ can be represented in spherical coordinates using the notation $\hat{g}\left(w_{r}, w_{\theta}, w_{\phi}\right)$, where $r=\sqrt{p^{2}+q^{2}+t^{2}}$, $\theta=\tan ^{-1}\left(\frac{q}{p}\right)$ and $\phi=\tan ^{-1}\left(\frac{\sqrt{p^{2}+q^{2}}}{t}\right)$ (ARAÚJO, 2013).

The mean values of the ordinates of the periodogram for similar values of $r$ investigate scale features of the point pattern under the hypotheses of isotropy. 
The $R$-spectrum $\hat{f}_{R}(r)$ is defined as

$$
\hat{f}_{R}(r)=\frac{1}{n_{r}} \sum_{r^{\prime}} \sum_{\theta} \sum_{\phi} \hat{g}\left(w_{r^{\prime}}, w_{\theta}, w_{\phi}\right), \quad r=1,2, \ldots
$$

where the total sum is divided by $n_{r}$ ordinates of the periodogram, for which $r-1<$ $r^{\prime} \leq r$.

The mean values of the ordinates of the periodogram for similar values of $\theta$ investigate directional features of the point pattern. The $\theta$-spectrum, $\hat{f}_{\theta}(\theta)$, is defined as

$$
\hat{f}_{\theta}(\theta)=\frac{1}{n_{\theta}} \sum_{r} \sum_{\theta^{\prime}} \sum_{\phi} \hat{g}\left(w_{r}, w_{\theta^{\prime}}, w_{\phi}\right), \theta=0^{0}, 10^{0}, 20^{0}, \ldots, 170^{0},
$$

where the total sum is divided by $n_{\theta}$ coordinates of the periodogram, for which $\theta-5^{0}<\theta^{\prime} \leq \theta+5^{0}$.

The mean values of the ordinates of the periodogram for similar values of $\phi$ investigate directional features of the point pattern. The $\phi$-spectrum, $\hat{f}_{\phi}(\phi)$, is defined as

$$
\hat{f}_{\phi}(\phi)=\frac{1}{n_{\phi}} \sum_{r} \sum_{\theta} \sum_{\phi^{\prime}} \hat{g}\left(w_{r}, w_{\theta}, w_{\phi^{\prime}}\right), \quad \phi=0^{0}, 10^{0}, 20^{0}, \ldots, 170^{0},
$$

where the total sum is divided by $n_{\phi}$ coordinates of the periodogram, for which $\phi-5^{0}<\phi^{\prime} \leq \phi+5^{0}$.

Using the additivity property of random variables with $\chi^{2}$ distribution, we have

$$
\sum_{r^{\prime}} \sum_{\theta} \sum_{\phi} \frac{\hat{g}\left(w_{r^{\prime}}, w_{\theta}, w_{\phi}\right)}{g\left(w_{r^{\prime}}, w_{\theta}, w_{\phi}\right)} \sim \frac{\chi_{2 n_{r}}^{2}}{2 n_{r}}
$$

where $\mathrm{r}=1,2, \ldots$

$$
\sum_{r} \sum_{\theta^{\prime}} \sum_{\phi} \frac{\hat{g}\left(w_{r}, w_{\theta^{\prime}}, w_{\phi}\right)}{g\left(w_{r}, w_{\theta^{\prime}}, w_{\phi}\right)} \sim \frac{\chi_{2 n_{\theta}}^{2}}{2 n_{\theta}}
$$

where $\theta=0^{0}, 10^{0}, 20^{0}, \ldots, 170^{0}$.

$$
\sum_{r} \sum_{\theta} \sum_{\phi^{\prime}} \frac{\hat{g}\left(w_{r}, w_{\theta}, w_{\phi^{\prime}}\right)}{g\left(w_{r}, w_{\theta}, w_{\phi}\right)} \sim \frac{\chi_{2 n_{\phi}}^{2}}{2 n_{\phi}}
$$

where $\phi=0^{0}, 10^{0}, 20^{0}, \ldots, 170^{0}$.

The original idea of Renshaw and Ford (1983) for performing the spectral analysis of spatial point patterns is to place the data on a fine two-dimensional grid. This idea can be easily expanded to the three-dimensional case where the positions of the events are allocated at the intersections of a fine three-dimensional grid.

The sample autocovariance is defined as 


$$
C_{i j k}=\frac{1}{m n o} \sum_{r=1}^{m-i n} \sum_{s=1}^{n-j} \sum_{\Omega_{u}} X_{r s u} X_{r+i, s+j, u+k}
$$

where $\Omega_{u}=1, \ldots, o-k ; k \geq 0$ or $\Omega_{u}=-k+1, \ldots, o ; k<0$ e $X_{r s u}$ is the matrix of observations corrected by the mean, where $r=1, \ldots, m ; s=1, \ldots, n ; u=$ $1, \ldots, o$.

In the three-dimensional case, the matrix is obtained by subtracting the value of the sample mean in each element of the matrix $M . O \times N$.

The periodogram can be calculated trough the sample autocovariance, as seen in the equation (43), by expanding the two-dimensional case presented by Renshaw and Ford (1983). Therefore, the periodogram is defined as

$$
\hat{f}\left(w_{p}, w_{q}, w_{t}\right)=\sum_{i=-m+1}^{m-1} \sum_{j=-n+1}^{n-1} \sum_{k=-o+1}^{o-1} C_{i j k} \cos \left(i w_{p}+j w_{q}+k w_{t}\right) .
$$

The spatial autocorrelation matrix is given by $\left\{\frac{C_{i j k}}{s^{2}}\right\}$, where $s^{2}$ is the sample variance of $\left\{X_{r s u}\right\}$. The spatial autocorrelation matrix measures the correlation of the data with each other, and it has central value given by $\frac{C_{000}}{s^{2}}=1$. given by

The equation (44) for the frequency values $\left(w_{p}, w_{q}, w_{t}\right)=\left(\frac{2 \pi p}{m}, \frac{2 \pi q}{n}, \frac{2 \pi t}{o}\right)$ is

$$
\hat{f}\left(\frac{2 \pi p}{m}, \frac{2 \pi q}{n}, \frac{2 \pi t}{o}\right)=m . n . o\left(a_{p q t}^{2}+b_{p q t}^{2}\right),
$$

where $a_{p q t}$ is the real part, and $b_{p q t}$ is the imaginary part of the equation (46) as

$$
a_{p q t}+i b_{p q t}=\frac{1}{m n o} \sum_{r=1}^{m} \sum_{s=1}^{n} \sum_{u=1}^{o} X_{r s u} e^{2 \pi i\left(\frac{p r}{m}+\frac{q s}{n}+\frac{t u}{o}\right)} .
$$

Developing the equation (46), we have

$$
\begin{aligned}
a_{p q t}+i b_{p q t} & =\frac{1}{m n o} \sum_{r=1}^{m} \sum_{s=1}^{n} \sum_{u=1}^{o} X_{r s u}\left\{\cos \left[2 \pi\left(\frac{p r}{m}+\frac{q s}{n}+\frac{t u}{o}\right)\right]\right. \\
& \left.+i \operatorname{sen}\left(2 \pi\left(\frac{p r}{m}+\frac{q s}{n}+\frac{t u}{o}\right)\right)\right\} .
\end{aligned}
$$

Thus,

$$
a_{p q t}=\frac{1}{m n o} \sum_{r=1}^{m} \sum_{s=1}^{n} \sum_{u=1}^{o} X_{r s u} \cos \left[2 \pi\left(\frac{p r}{m}+\frac{q s}{n}+\frac{t u}{o}\right)\right]
$$

$$
b_{p q t}=\frac{1}{m n o} \sum_{r=1}^{m} \sum_{s=1}^{n} \sum_{u=1}^{o} X_{r s u} \operatorname{sen}\left[2 \pi\left(\frac{p r}{m}+\frac{q s}{n}+\frac{t u}{o}\right)\right] .
$$

The frequency range is about $p=0, \ldots, m-1 ; \quad q=0, \ldots, n-1 ; \quad t=0, \ldots, o-1$. 


\section{$3 \quad$ Material and methods}

We have simulated three typical three-dimensional spatial point patterns with structures of spatial dependence associated with complete spatial randomness (CSR), cluster and inhibition processes.

Figure 1 shows a realization of 675 simulated events within a unit cube following the homogeneous Poisson process or CSR.

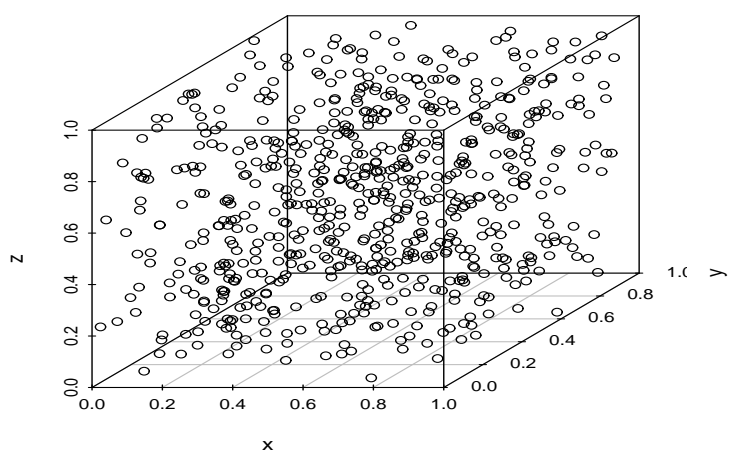

Figura 1 - Typical realization of a homogeneous Poisson process with 675 events distributed in a $3 \mathrm{D}$ space.

Figure 2 shows a typical realization of a three-dimensional point pattern with 870 simulated events with strong evidence for clustering.

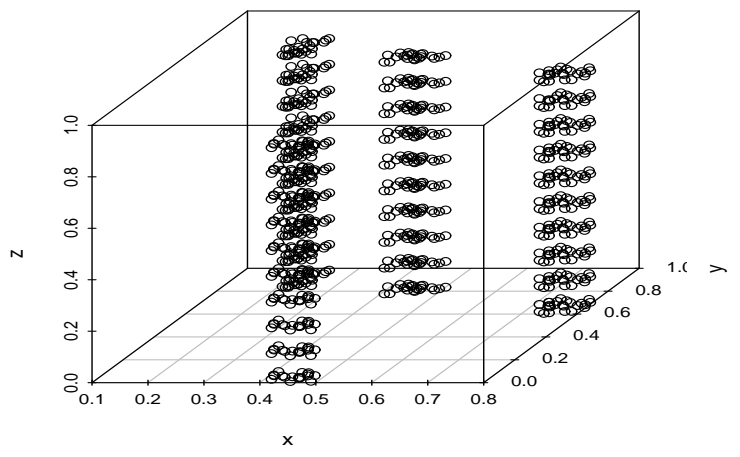

Figura 2 - Typical realization of a point pattern with 870 events distributed in clusters in a $3 \mathrm{D}$ space.

Figure 3 shows a typical realization of a three-dimensional point pattern with 264 events of a regular point process with inhibition distance equal to $\delta=0.1$. 


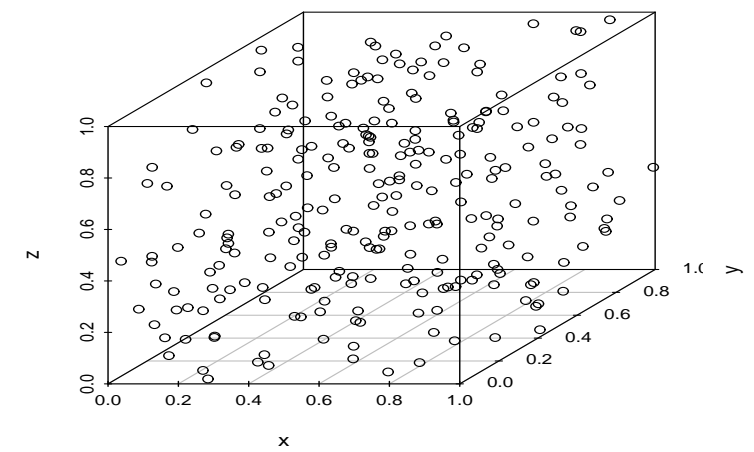

Figura 3 - Typical realization of a point pattern with 264 events regularly distributed in a 3D space with inhibition distance equal to $\delta=0.1$.

These three typical realizations of 3D spatial point patterns will be analyzed using both: a fine 3D regular grid with $M \times N \times O$ knots, and the three-dimensional spectral theory developed in the previous sections (equations (43), (45), (48), and (49)).

All analyzes were performed using functions developed in software R (R CORE TEAM, 2020).

\section{Results and discussion}

It is well known that the idea of complete spatial randomness (CSR) provides a useful benchmark against which to compare observed patterns. A stochastic model for a CSR is the homogeneous Poisson process in which points are distributed uniformly across the space independently of one to another (DIGGLE, 2003).

Mugglestone and Renhaw (1996) affirm that the spectrum of the CSR contains all frequencies to the same degree. Thus, to detect departures from CSR, in an exploratory way, it is necessary to examine the shape of the periodogram to decide whether it is flat (characteristic shape of a periodogram associated with CSR) or not flat (various alternatives to CSR). 
Figure 4 shows the periodogram of the 3D spatial point pattern presented in Figure 1. The shape of the periodogram is broadly flat, reflecting the absence of structure in the three-dimensional simulated spatial point pattern. The observed fluctuations in this periodogram are entirely due to sampling variations.

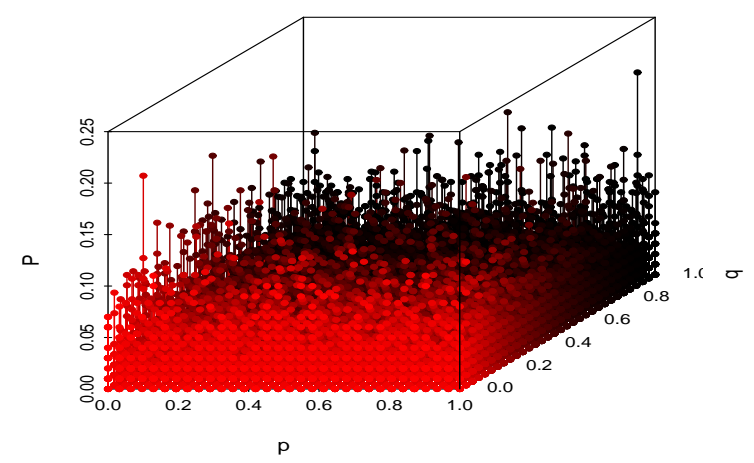

Figura 4 - Periodogram of the simulated three-dimensional homogeneous Poisson point pattern.

One of the alternatives to CSR occurs when events display clustering (Figure 2 ). It is obvious from Figure 2 that there is strong clustering of events in the spatial pattern. The shape of the periodogram for spatial cluster point patterns should exhibit very large low frequency values at all angles (MUGGLESTONE and RENSHAW, 1996). Also, the periodogram features a constant flat shape close to zero. That is exactly we can observe in the periodogram presented in figure 5 . Thus, the periodogram shows evidences for clustering of events in the spatial point pattern presented in Figure 2.

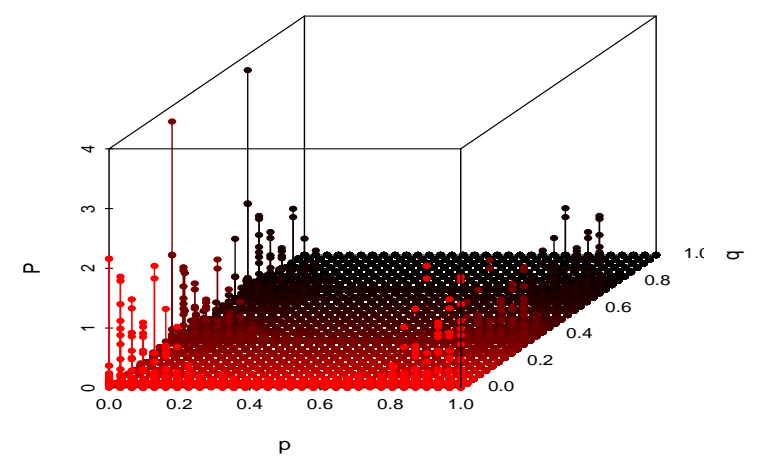

Figura 5 - Periodogram of the simulated three-dimensional clustered spatial point pattern. 
Although the map of the pattern (Figure 3) shows evidence of a minimum inter-event distance (inhibition distance), the underlying regular structure is almost impossible to detect by eye. The shape of the periodogram of regular patterns should have very small low frequency values, and feature a broadly constant flat shape different from zero, as we can see in figure 6 . Thus, the periodogram of the spatial point pattern presented in Figure 3 shows evidence of having a minimum inhibition distance.

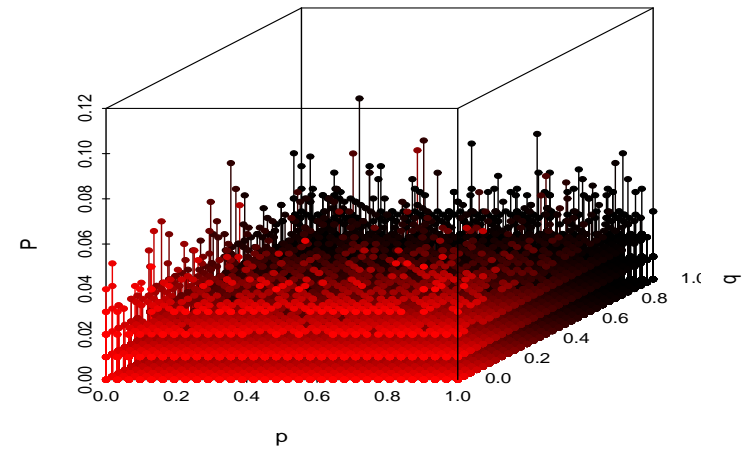

Figura 6 - Periodogram of the simulated regular three-dimensional spatial point pattern.

Although these results show that the spectral analysis can be competitive with the analysis based on the space domain for the characterization of three-dimensional spatial point patterns, some problems must be kept in mind that may limit a wider diffusion of its application.

First, spectral theory is, in general, more difficult to understand than theory in the space domain. For example, Haining (1982) believes that spectral analysis "may provide considerable insight into the structure of point patterns, but the need for large data sets, the arbitrary nature of the smoothing procedures, and the complicated statistical inference problems have all discouraged its wider use".

In addition, the spectral theory for spatial point pattern analysis is dispersed in the literature, while the theory in the space domain is consolidate and available in several books (DIGGLE, 2003; BADDELEY et al., 2015).

Another problem refers to the absence of computer programs available to carry out spatial spectral analysis. We would like to point out that all $\mathrm{R}$ functions used in this paper are available on request to the first author.

Finally, we should observe that spectral spatial analysis, more than a competitive tool, it is an alternative tool that can be used concurrently with space domain methods to investigate three-dimensional spatial point patterns. 


\section{Conclusions}

This paper aimed both: to present theoretical aspects involved in spectral analysis of three-dimensional spatial point patterns, and to show how this theory can be used in the exploratory analysis of such patterns.

We demonstrated that the theory of spectral analysis of three-dimensional spatial point patterns can be developed as an extension of the theory of twodimensional point processes.

We also showed that the spectral methods developed in this paper were able to correctly identify three typical three-dimensional simulated spatial point patterns (complete spatial randomness (CSR), regularity and clustering).

In this work, the spectral theory was used only to generate periodograms, whose shapes were analyzed visually. It is well known that exploratory analysis based on visual inspection is dependent on the observer, which is not recommended. However, the theory presented in this work makes it possible to develop more formal methods of analysis than exploratory analysis. Thus, it's worth pointing out that other works are under way by the authors in order to develop formal methods based on spectral framework for testing against the hypothesis of complete spatial randomness in three-dimensional spatial point patterns.

\section{Acknowledgments}

We would like to thank reviewers and editors for their comments and suggestions.

ARAUJO, E. S. B.; SCALON, J. D.; BATISTA, L. S. Análise espectral exploratória em configurações pontuais em espaços tridimensionais. Rev. Bras. Biom., Lavras, v.39, n.1, p.177-193, 2021. 
- RESUMO: Uma configuração pontual espacial é uma coleção de pontos localizados irregularmente dentro de uma área (2D) ou espaço (3D) que foram gerados por algum mecanismo estocástico. Exemplos de padrões pontuais incluem localizações de árvores em uma floresta, de casos de uma doença em uma região ou de partículas em uma seção microscópica de um material compósito. A análise de padrões pontuais é usada para determinar a ausência (completa aleatoriedade espacial) ou presença (regularidade e agrupamento) de estrutura de dependência espacial dos eventos no espaço. Métodos no domínio espacial são amplamente utilizados para esse fim, enquanto os métodos conduzidos no dominio da frequência (análise espectral) ainda são desconhecidos para a maioria dos pesquisadores. A análise espectral é uma ferramenta poderosa para investigar padrões de pontos espaciais, uma vez que não assume, a priori, características estruturais de dados (por exemplo, isotropia) e usa apenas a função de autocovariância e sua transformada de Fourier. Existem alguns métodos baseados nas estruturas espectrais para analisar padrões de pontos espaciais 2D. Nao existem tais métodos disponíveis para a situação $3 D$ e, portanto, o objetivo deste trabalho é desenvolver novos métodos baseados no domínio espectral para análise de padrões de pontos tridimensionais. A ênfase está em relacionar a estrutura do periodograma ao processo estocástico que gerou uma configuração pontual 3D. Os resultados mostram que os métodos baseados em análise espectral propostos neste trabalho são capazes de, corretamente, identificar padrões de processos pontuais tridimensionais típicos, podendo ser utilizados, concomitantemente, com análises no domínio espacial para uma melhor caracterização dos padrões pontuais.

- PALAVRAS-CHAVE: Análise espacial; domínio da frequência; processos pontuais; transformada de Fourrier; periodograma.

\section{Referências}

ARAÚJO, E. S. B. Análise espacial espectral em processos pontuais., 2013. 77p. Thesis (Ph.D) - Universidade Federal de Lavras, Brazil, 2013.

ARAÚJO, E. S. B.; SCALON, J. D.; BATISTA, L. S. Análise espacial espectral bidimensional em particulas de material composito Al/SiC. TEMA, v.15, p.073-081, 2014.

BADDELEY, A.; RUBAK, E.; TURNER, R. Spatial point patterns: Methodology and applications with $R$. London: Chapman and Hall/CRC Press, 2015.

BADDElEY, A. J.; MOYEED, R., A., HOWARD, C., V. Analysis of a threedimensional point pattern with replication. Royal statistical society, v.42, n.4, p. 641-668, 1993.

BARTLETT, M. S. The spectral analysis of two-dimensional point processes. Biometrika, v.51, p.299-311, 1964. 
BRAENDGAAR, H.; GUNDERSEN, H. J. G. The impact of recent stereological advances on quantitative studies of the nervous system. Neuroscience Methods, v.18, p.39-78, 1986.

DIGGLE, P. J. Statistical analysis of spatial point patterns. Oxford: Oxford University Press, 2003. 288p.

HAINING, R., Describing and modeling rural settlement maps, Annals of the Association American Geography, v.72, p.211-223, 1982.

MAGAlHÃES, M. N. Probabilidade e variáveis aleatórias. 2.ed. São Paulo: Edusp, 2006. 424p.

MUGGLESTONE, M. A.; RENSHAW, E. Spectral tests of randomness for spatial point patterns. Environmental and Ecological Statistic, v.8, p.237-251, 2001.

MUGGLESTONE, M. A.; RENSHAW, E. A practical guide to the spectral analysis of spatial point processes. Computational Statistics and Data Analysis, v.21, p.4365, 1996.

$\mathrm{R}$ CORE TEAM, R: a language and environment for statistical computing. $\mathrm{R}$ Foundation for Statistical Computing, Vienna, 2020.

RENSHAW, E.; FORD, D. The interpretation of process from pattern using twodimensional spectral analysis: methods and problems of interpretation. Journal of the Royal Statistical Society, B, v.32, n.1. p.51-63, 1983.

RENSHAW, E.; FORD, D. The descriptions of spatial using two-dimensional spectral analysis. Vegetatio, v.56, p.75-85, 1984.

Received on 07.09.2020.

Approved after revised on 08.02.2021. 